BNL - 66939

\title{
Synchrotron X-ray Microtomography, Electron Probe Microanalysis, and NMR of Toluene Waste in Cement
}

Leslie G. Butler, Frank K. Cartledge, Andrew J. Wales, Pamela L. Bryant and Earl F. Emery Department of Chemistry, Louisiana State University

Baton Rouge, LA 70803

John W. Owens

Department of Chemistry, Southern University

Baton Rouge, LA 70813

Richard L. Kurtz

Physics \& Astronomy, Louisiana State University

Baton Rouge, LA 70803

Gary R. Byerly and Xiaogang Xie

Geology \& Geophysics

Baton Rouge, LA 70803

Betsy Dowd

National Synchrotron Light Source

Brookhaven National Laboratory

Upton, NY 11973

July 1999

\section{National Synchrotron Light Source}

\author{
Brookhaven National Laboratory \\ Operated by \\ Brookhaven Science Associates \\ Upton, NY 11973
}

Under Contract with the United States Department of Energy

Contract Number DE-AC02-98CH10886 


\section{DISCLAIMER}

This report was prepared as an account of work sponsored by an agency of the United States Government. Neither the United States Government nor any agency thereof, nor any of their employees, nor any of their contractors, subcontractors or their employees, makes any warranty, express or implied, or assumes any legal liability or responsibility for the accuracy, completeness, or any third party's use or the results of such use of any information, apparatus, product, or process disclosed, or represents that its use would not infringe privately owned rights. Reference herein to any specific commercial product, process, or service by trade name, trademark, manufacturer, or otherwise, does not necessarily constitute or imply its endorsement, recommendation, or favoring by the United States Government or any agency thereof or its contractors or subcontractors. The views and opinions of authors expressed herein do not necessarily state or reflect those of the United States Government or any agency thereof. 
To be submitted to Environmental Science \& Technology

"Synchrotron X-ray Microtomography, Electron Probe Microanalysis, and NMR of Toluene Waste in Cement"

by Leslie G. Butler1, John W. Owens ${ }^{2}$, Frank K. Cartledge1, Richard L. Kurtz 3 , Gary R. Byerly4, Andrew J. Wales 1 , Pamela L. Bryant1, Earl F. Emery1, Betsy Dowd ${ }^{5}$, and Xiaogang Xie ${ }^{4}$.

a contribution from the

Departments of ${ }^{1}$ Chemistry, ${ }^{3}$ Physics \& Astronomy, and ${ }^{4}$ Geology \& Geophysics

Louisiana State University

Baton Rouge, LA 70803,

2Department of Chemistry

Southern University

Baton Rouge, LA 70813, and

5 National Synchrotron Light Source

Brookhaven National Laboratory

Upton, NY 11193

\begin{abstract}
Synchrotron X-ray microtomography shows vesicular structures for toluene/cement mixtures, prepared with 1.22 to $3.58 \mathrm{wt} \%$ toluene. Three-dimensional imaging of the cured samples shows spherical vesicles, with diameters ranging from 20 to $250 \mu \mathrm{m}$; a search with EPMA for vesicles in the range of $1-20 \mu \mathrm{m}$ proved negative. However, the total vesicle volume, as computed from the microtomography images, accounts for less than $10 \%$ of initial toluene. Since the cements were cured in sealed bottles, the larger portion of toluene must be dispersed within the cement matrix.

Evidence for toluene in the cement matrix comes from ${ }^{29}$ Si MAS NMR spectroscopy, which shows a reduction in chain silicates with added toluene. Also, ${ }^{2} \mathrm{H}$ NMR of $\mathrm{d} 8$ toluene/cement samples shows high mobility for all toluene and thus no toluene/cement binding.

A model that accounts for all observations follows: For loadings below about 3 $w t \%$, most toluene is dispersed in the cement matrix, with a small fraction of the initial toluene phase separating from the cement paste and forming vesicular structures that are preserved in the cured cement. Furthermore, at loadings above 3 $w t \%$, the abundance of vesicles formed during toluene/cement paste mixing leads to macroscopic phase separation (most toluene floats to the surface of the cement paste).
\end{abstract}




\section{Introduction}

Synchrotron X-ray microtomography, electron probe microanalysis (EPMA), and solid-state nuclear magnetic resonance (NMR) spectroscopy are used as a complementary set of techniques to probe toluene/cement structure. Microtomography yields three-dimensional images of the samples, roughly cubic sections nearly a millimeter on a side, with a digital resolution here of $7.2 \mu \mathrm{m}$. This is the first application of microtomography for examining waste stabilization in a cement matrix.

Cements and similar materials are used to stabilize/solidify a variety of hazardous wastes. ${ }^{1-6}$ The technology has two broad mechanisms of action: physical isolation of the wastes through formation of a relatively impermeable solid matrix and chemical interactions that alter the chemical speciation of the waste or bind the waste to the matrix. The first mechanism acting by itself is generally insufficient to assure environmental isolation of the wastes, since the common matrix materials, such as portland cement, have an elaborate, often connected, pore system that allows material transport.7,8 Thus, characterization of the chemical interactions occurring during solidification/stabilization (S/S) is an important goal of research into this technology.

Despite increasing understanding of $\mathrm{S} / \mathrm{S}$ in both a fundamental and applied sense, one aspect of the technology continues to be controversial; namely, the applicability to wastes containing organic materials. Numerous publications can be cited which contain statements to the effect that cement-based S/S, often with appropriate additives, has real potential for treatment of waste streams or contaminated soils that contain organics.9-12 Furthermore, many actual remediations of waste sites contaminated with organics have been carried out using cement-based $\mathrm{S} / \mathrm{S}$, usually with some secondary containment system such as slurry walls or liners. 13-15 Nevertheless, there are also literature statements such as: "The available data regarding the $\mathrm{S} / \mathrm{S}$ of organics do not demonstrate the effectiveness of this treatment method."16 Several problems with organics are often cited, including interferences with cement setting reactions and lack of strong chemical interaction with matrix materials.

The present paper describes the application of techniques not previously used to study S/S, leading to a new understanding of the process as applied to organics. This work looks at toluene encapsulated in portland cement as an example in which little 
chemical interaction between organic waste and the matrix is expected. Toluene has limited solubility in water, $535 \mathrm{mg} / \mathrm{L}$ at $25{ }^{\circ} \mathrm{C} .17$ Thus, a reasonable expectation during cement solidification would be phase separation from the cement paste in the form of randomly dispersed vesicles. Significant questions are: what is the size of these vesicles, is the vesicular structure dependent upon toluene loading, and is all toluene contained within the vesicles?

\section{Experimental Section}

Sample Preparation. Seven toluene/cement samples were prepared for microtomographic analysis. Samples were prepared with Type I portland cement, deionized water, and toluene in the quantities listed in Table 1. Each toluene/cement sample was prepared by mixing cement, water, and toluene in a plastic bowl and stirring thoroughly. However, for the two samples with initial toluene concentration greater than $3 \%$, some toluene remained pooled atop the cement paste even after fifteen minutes of mixing. The cement/toluene slurry was then poured into $20 \mathrm{~mL}$ scintillation vials and sealed. While some toluene does evaporate during mixing, based on our previous experience with total leaching of toluene from toluene/cement mixtures, reliable sample preparations and curing in sealed scintillation vials is expected for the $<3 \mathrm{wt} \%$ toluene/cement samples. 5 Samples were cured at ambient temperature for two months. Just prior to microtomography, the glass vials were scored with a file, broken open, and the intact cement blocks weighed in air. A diamond-tipped core drill yielded cylindrical samples $5 \mathrm{~mm}$ in diameter and 5 to 10 $\mathrm{mm}$ long. As formed, the $5 \mathrm{~mm}$ thick samples were too optically dense at $18 \mathrm{keV}$ for analysis. With file and emery cloth, the cylinders were reshaped to irregular polygons with maximum dimension along the $X$-ray path of $3 \mathrm{~mm}$. Samples made with perdeuterated toluene were handled similarly, though sized to fit within $5 \mathrm{~mm}$ NMR sample tubes. In addition, the $\mathrm{d} 8$-toluene/cement samples were stored in capped vials and refrigerated between NMR experiments so as to retard d8-toluene evaporation. ${ }^{2} \mathrm{H}$ 
NMR was done after two weeks of cure.

Table 1. Composition of Toluene/Cement Samples and Microtomography Results

$\begin{array}{cccccc}\text { sample } & \text { cement/g } & \text { water/g } & \text { toluene/g } & \text { \%toluene(wt/wt) } & \text { Voxels } \\ 1 & 50 & 19 & 0.866 & 1.24 & 1530 \\ 2 & 50 & 18 & 1.732 & 2.48 & 7493 \\ 3 & 50 & 17 & 2.598 & 3.73 & 2851 \\ 4 & 50 & 20 & 0.0 & 0.0 & 0 \\ 5 & 50 & 20 & 0.866 & 1.22 & 2864 \\ 6 & 50 & 20 & 1.732 & 2.41 & 6434 \\ 7 & 50 & 20 & 2.598 & 3.58 & 665 \\ 8 & 15 & 5.5 & 0.52^{\mathrm{b}} & 2.5 & \text { not measured } \\ 9 & 15 & 5.3 & 0.7 \mathrm{~b} & 3.33 & \text { not measured }\end{array}$

aNumber of voxels counted in the sample with an X-ray absorptivity less than $3.3 \times 10^{-4}$ O.D./voxel. The total number of voxels in the cropped 3D data set for each sample is $1.575 \times 10^{6}(=150 \times 150 \times 70)$.

$b_{\mathrm{d} 8 \text {-toluene. }}$

Summary of Cure Times: For microtomography, all samples were cured for two months in sealed vials, then broken out the day of the imaging. The same samples were latter examined by EPMA after 8 months total cure, and by solid-state ${ }^{13} \mathrm{C}$ and ${ }^{29} \mathrm{Si}$ NMR at 9 months. The d8-toluene/cement samples were studied after a cure of two weeks.

Microtomography. Synchrotron X-ray microtomography was performed at Beamline X27A at the National Synchrotron Light Source, Brookhaven National Laboratory with aluminum/zirconium filtered white radiation from a bending magnet and a synchrotron beam energy of $2.5 \mathrm{GeV}$. The peak X-ray flux after filtering was centered at about $18 \mathrm{keV}$ which is sufficiently penetrating to pass through $3 \mathrm{~mm}$ thick cement samples with minimum beam hardening 18 ; the samples had a maximum absorptivity of 0.13 O.D. The absorptivity of the samples calculated from the raw data were used to renurmalize the absorptivity values of the microtomography 
data. A YAG:Ce scintillator with peak emssion at $550 \mathrm{~nm}$ was used to convert the $X-$ ray projection data into a visible image, which was then focused via a $45^{\circ}$ mirror and a microscope objective onto the $\mathrm{CCD}$ camera. The projection data were acquired with a Photometrics PXL camera interfaced to a SGI Indy; the camera contained a Kodak KAF-6300 CCD with $9 \mu \mathrm{m}$ square pixels in a $3072 \times 2048$ array and sampled with a 12-bit digitizer. For the 3D imaging, the exposure time per projection was 0.3 to 1.0 secs (depending mainly upon synchrotron beam current), with $4 \times 4$ binning and a field of view of $767 \times 120$ square pixels. The digital resolution of $7.2 \mu \mathrm{m}$ was based on the $4 \times 4$ binning and $X 5$ optical magnification between the scintillator and the camera. A total of 451 projections were acquired at $0.40^{\circ}$ increments for sample rotations spanning $180^{\circ}$. The CCD images were corrected for white field response. Two-dimensional slice images were taken using a fast Fourier filtered back-transform algorithm that implements a gridding technique for fitting to cartesian coordinates. 19,20 Some reconstructions were done on an 8-node symmetric multiprocessing Pention farm. Three-dimensional volume data sets constructed from a sequence of slices; 120 slices

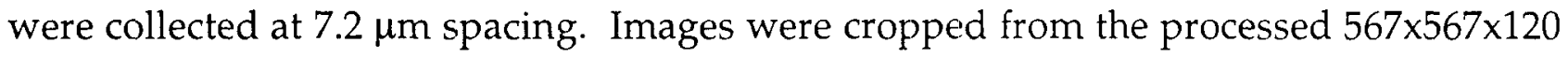
voxel data sets to $150 \times 150 \times 70$ voxel data sets so as to exclude exterior sample surfaces.

NMR Spectroscopy. ${ }^{29}$ Si MAS NMR spectra were collected on a Chemagnetics Infinity $400 \mathrm{MHz}$ with a $4.5 \mu \mathrm{s} 90^{\circ} 29 \mathrm{Si}$ pulse, proton decoupling, and CYCLOPS phase cycling.21,22 The pulse recycle delay was $1 \mathrm{~s}$ and the MAS spin rate was $6 \mathrm{kHz}$. The chemical shift was set based on the $-9.9 \mathrm{ppm}$ resonance in tetrakis(trimethylsilyl)silane (TTMSS) used as an external reference. Zirconia rotors, $7.5 \mathrm{~mm}$ outer diameter, holding a sample volume of about $300 \mathrm{~mm}^{3}$ were used. From the solid cement samples after nine months of cure, five mm diameter cores were drilled, inserted into the rotor, and empty spaces packed with $\alpha-\mathrm{Al}_{2} \mathrm{O}_{3}$. In some cases, instead of cores, partially crushed cement fragments were used. ${ }^{2} \mathrm{H}$ NMR was done with a high-power static probe and a quadrupolar echo pulse sequence. 23,24 
Electron Probe Microanalysis (EPMA). Two samples, after 8 months of cure, were set into epoxy, cut with a water-cooled diamond saw, and ground and coarsepolished with alumina, fine-polished with diamond, and carbon sputter-coated to insure a conductive surface for EPMA imaging and analysis. Images were obtained with a JEOL 733 superprobe with secondary electron detector (for surface irregularities), backscatter electron detector (for compositional variation, since the backscatter coefficient is a function of average atomic number), and X-ray mapping using energy dispersive x-ray detector. Quantitative analysis was done by four wavelength dispersive $x$-ray detectors, using silicate and carbonate standards, and correcting for matrix absorption, fluorescence, and atom number. Though $\mathrm{H}_{2} \mathrm{O}$ cannot be measured directly by these techniques, it is commonly estimated to within $1 \mathrm{wt} \%$ by difference from $100 \%$ of the oxides analyzed.

\section{Results and Discussion}

Two issues are addressed in this work: Does microtomographic imaging provide new insight into waste/cement interactions? What is the fate of toluene in toluene/cement mixtures? In this work, microtomography easily answered some questions, but other questions arose which were better addressed with EPMA and solid-state NMR studies.

The microtomographic images show that toluene leads to vesicle formation in the cured cement, as seen in these renderings of the 1.24 and $2.49 \mathrm{wt} \%$ toluene/cement samples (Figure 1). The view shown is cropped, or extracted, from a larger image of the sample cross section. Cropping is done to eliminate surface artifacts from the analysis; dust at the sample surface is not shown in these interior images. The image dimensions are $0.972 \mathrm{~mm} \times 0.972 \mathrm{~mm} \times 0.583 \mathrm{~mm}$, corresponding to a $1 \mathrm{mg}$ sample mass and a 15 Mbyte data set. Not shown is an image of $0 \mathrm{wt} \%$ toluene/cement; the cement grain structure is similar to those in Figure 1, but lacks vesicles. 
The vesicles are roughly spherical, are randomly distributed throughout the sample, and have diameters ranging from 20 to $250 \mu \mathrm{m}$. The X-ray absorption of the cement ranges from $3.5-8 \times 10^{-4}$ O.D./voxel while the vesicles are less than $3.3 \times 10^{-4}$ O.D./voxel. The contrast between cement matrix and vesicles allows convenient visualization of the vesicle structures with an isosurface plot, as shown in Figure $2 a, b$ for 1.24 and $2.49 \mathrm{wt} \%$ toluene/cement samples. The isosurfaces are computed at an Xray absorption of $3.3 \times 10^{-4}$ O.D./voxel. No vesicles are found in the reference cement sample, $0 \mathrm{wt} \%$ toluene/cement, therefore, vesicles are correlated with toluene concentration. On the basis of the poor solubility of toluene in water, $535 \mathrm{mg} / \mathrm{L}$ at 25 ${ }^{\circ} \mathrm{C} 17$, the low $\mathrm{X}$-ray absorptivity of the vesicles, and the correlation of vesicles with toluene loading, the vesicles contents are assigned as toluene. It is not known if, at the time of microtomography, the vesicles were filled with toluene. Because of the small sample size, sample heating from the X-ray beam, and the volatility of toluene, the vesicles may have been filled with air. In this sense, the structures are the fossil remains of toluene-filled vesicles formed in the first hours of the cement cure.

Volumetric analysis of a three-dimensional image encompasses a wide range of techniques, ranging from simple histogram analysis to thresholding and octree decomposition. 25,26 For this work, the total vesicular volume is calculated by counting 27 all voxels with $X$-ray absorptivity less than $3.3 \times 10^{-4}$ O.D./voxel; these counts are listed in Table 1.

Shown in Figure 3 is a plot of total vesicular volume for each sample, converted to $\mathrm{wt} \%$ toluene/cement, versus the $\mathrm{wt} \%$ initial toluene/cement in the cement paste. The conversion from counted voxels to $w \mathrm{t} \%$ toluene/cement is done via

$$
\begin{gathered}
\text { wt } \% \text { toluene } \\
\text { in vesicles }
\end{gathered}=100 \times \frac{\sum \text { voxels with absorbance }<3.3 \times 10^{-4} \text { O.D. }}{\sum \text { all voxels }} \times \frac{\rho(\text { toluene })}{\rho(\text { cement })}
$$

where the density of toluene is $0.8669 \mathrm{~g} / \mathrm{cm}^{3}$ and the density of cured cement is 2 $\mathrm{g} / \mathrm{cm}^{3} .7$ There is a distinct trend in the measured fraction of toluene found in 
vesicles. First, there appears to be a minimum of $0.7 \mathrm{wt} \%$ initial toluene/cement required for vesicular formation, based on a linear fit through the four data points in the range 1.22 to $2.48 \mathrm{wt} \%$ initial toluene/cement. Second, the observation made during sample preparation of samples with $>3 \mathrm{wt} \%$ initial toluene/cement, a pooling of toluene atop the cement paste, is reflected as a reduction in total vesicular volume in the cured cement. As a guide for further discussion, these two factors are summarized in Figure 3 with a preliminary fit to the data; the solid line shows the threshold with a linear function and the dashed line reflects the gross phase separation observed during sample preparation.

It is useful to consider the hypothetical situation of encapsulation of all toluene in vesicles. In this limit, the maximum possible $w t \%$ toluene in vesicles has a slope of unity, with a threshold ( $\mathrm{x}$-intercept) given by toluene solubility in water, as shown in Figure 3 (dotted line). The difference between the dotted and solid lines indicates the amount of toluene dispersed within the cement matrix (see insert in Figure 3). Here, dispersed means toluene that is contained within the cement matrix in a form other than as a liquid within $20-250 \mu \mathrm{m}$ vesicles. On the basis of the microtomography data, the fraction of dispersed toluene is quite large, always more than $90 \%$ of all toluene (excluding the $>3 \mathrm{wt} \%$ samples for which toluene pooled atop the cement paste).

Toluene dispersed in the cement matrix is invisible in the microtomography experiment. There is no significant image contrast between the cement matrix and the cement matrix containing 1-2 wt\% dispersed toluene. Image contrast could be created by chemical modification, for example, bromine- or iodine-containing toluene analogs. Since we wish to focus on toluene, the search for evidence of toluene dispersed in the cement matrix continues with other experimental techniques.

One possible fate for the dispersed toluene is inclusion in vesicles with a size smaller than can be seen by microtomography. A search for vesicles in the range of 1$20 \mu \mathrm{m}$ was done with EPMA (backscattering), Figure $4 \mathrm{a}, \mathrm{b}$, for 0 and $3.58 \mathrm{wt} \%$ 
toluene/cement, respectively. These $2 \mathrm{D}$ images show and confirm the larger vesicles observed earlier with microtomography, but they do not show a significant number of $1-20 \mu \mathrm{m}$ vesicles. On the basis of critical size stability for emulsions 28 and growth theory for crystals and vesicles, especially as recast for cement hydration 29,30 , this is not an unexpected result. In brief, in the cement paste, a small liquid-filled vesicle with a high surface-to-volume ratio is not thermodynamically stable with respect to larger vesicles and lower surface-to-volume ratios. However, mass transport limits the ultimate size of the toluene-filled vesicles, which are formed during initial cement mixing and the early stages of cement cure.

A second possible fate of dispersed toluene is within the cement-silicate-hydrate gel phase (CSH gel). If so, toluene may affect the cement grain chemistry. It is wellknown that organic liquids do reduce the final cement strength. ${ }^{7}$ The high wt\% toluene/cement samples in this study were noticeably softer than the plain cement sample. Normally in hydrated cement, cement grains (nominally, tricalcium silicate) are surrounded by a reaction zone consisting of CSH gel, the main structural phase of cement.7,29,30 In cement hydration, the cement grain slowly dissolves in water, releasing calcium and silicate ions that react and precipitate as $\mathrm{CSH}$ gel. Cement chemistry was measured with EPMA elemental analysis and solid-state ${ }^{29} \mathrm{Si}$ NMR. The high-resolution EMPA images, Figure 4a,b, show the cement grains with dimensions of $10-20 \mu \mathrm{m}$. A comparison of the reaction zone chemistry for the two samples, as measured by EPMA elemental analysis, Figure 5, shows only a minor difference. Another measure of cement chemistry comes from ${ }^{29} \mathrm{Si}$ NMR spectroscopy. The peaks labeled $\mathrm{Q}_{0}, \mathrm{Q}_{1}$, and $\mathrm{Q}_{2}$, are assigned to monomeric, dimeric, and chain silicate units, respectively. Unreacted cement grains contain only monomeric silicate, so the growth of the $\mathrm{Q}_{1}$ and $\mathrm{Q}_{2}$ peaks at the expense of $\mathrm{Q}_{0}$ is a measure of the extent of cement hydration. 31,32 The Q2 peak, attributed to chain silicate units, is reduced in amplitude as toluene is added to the cement, Figure 6 and 
Table 2. This is a clear indication of intimate contact between toluene and the cement phase, much more than can be expected for toluene encapsulated in vesicles, and therefore, largely separated from cement chemistry.

Table 2. ${ }^{29} \mathrm{Si}$ NMR Results

$\begin{array}{lrrrc}\text { wt\% Toluene } & \% \text { Q0 } & \% Q_{1} & \% Q_{2} & \% \text { hydration } \\ 0 & 37 & 38 & 25 & 63 \\ 1.22 & 40 & 44 & 16 & 60 \\ 1.24 & 40 & 44 & 16 & 60 \\ 2.41 & 38 & 51 & 11 & 62 \\ 2.48 & 62 & 23 & 15 & 38 \\ 3.58 & 39 & 36 & 25 & 61 \\ 3.73 & 40 & 46 & 14 & 60\end{array}$

Can dispersed toluene be detected directly? We explored this issue with both ${ }^{2} \mathrm{H}$ and ${ }^{13} \mathrm{C}$ NMR spectroscopy. While ${ }^{13} \mathrm{C}$ NMR is attractive for use with nonisotopically enriched toluene, our tests showed that the low loadings and possibly large line widths prevented effective ${ }^{13} \mathrm{C}$ NMR spectroscopy. Useful spectra were not acquired either with a cross polarization/magic angle spinning or with a single pulse (with proton decoupling) experiment. Hence, we explored isotopically-enriched toluene/cement samples with the use of $\mathrm{d} 8$-toluene. Solid-state ${ }^{2} \mathrm{H}$ NMR spectra of freshly prepared 2.5 and $3.33 \mathrm{wt} \% \mathrm{~d} 8$-toluene/cement show a single liquid-like resonance. The liquid-like resonance is consistent with $\mathrm{d} 8$-toluene encapsulated in vesicles. Interestingly, there was no evidence of a second toluene component with a solid-state like resonance, i.e., d8-toluene entrapped in the cement matrix so tightly as to restrict molecular motion. 23 This observation indicates that toluene, even when dispersed in the cement matrix, is not chemically bound to the cement phase, but 
rather remains highly mobile at the molecular scale.

\section{Conclusion}

Synchrotron X-ray microtomography is an effective imaging technique for probing waste structures in matrices. The $3 \mathrm{D}$ images have the necessary resolution to observe features at distance scales important to the sample. Also, the 3D images are intellectually stimulating, leading to additional inquiries with high-resolution 2D EPMA and solid-state NMR spectroscopy.

The toluene/cement system shows the complementary nature of three experiments: 3D tomography, high-resolution 2D electron microscopy (including elemental analysis), and solid-state NMR spectroscopy. Microtomography shows a minor toluene component exists as vesicles with sizes from 20 to $250 \mu \mathrm{m}$. EPMA shows no significant vesicle structure unique to the toluene/cement samples at a size below the $7.2 \mu \mathrm{m}$ digital resolution of tomography images. The microprobe elemental analysis shows a slight change in the reaction chemistry of the cement grains as a function of added toluene, an observation which is supported by the solid-state ${ }^{29} \mathrm{Si}$ NMR spectra. Also, direct observation of toluene was made with ${ }^{2} \mathrm{H}$ NMR of $\mathrm{d} 8$-toluene/cement samples; the spectra show a single toluene component having liquid-like mobility. The conclusion reached is that most toluene is intimately mixed at the molecular level with the cement matrix, yet retains high molecular mobility. A smaller component forms discrete vesicles. Lastly, at high initial loadings, the toluene-filled vesicles agglomerated during mixing, gross phase separation occurs, and toluene floats to the surface of the cement paste.

\section{Acknowledgements}

All work on the X-ray computed microtomography instrument at NSLS was funded in part by DOE grant No. DE-AC02-76CH00016, Office of Energy Research. 
Research into the chemistry of waste/cement interactions was funded by EPA grant No. R82-0024-010 (Cartledge and Butler) and NSF CHE-9634060 (Butler, Owens, and Cartledge). Grants from the Louisiana Board of Regents supported the microprobe (Byerly) and NMR (Butler and Cartledge) facilities.

\section{References}

(1) Conner, J. R. Chemical Fixation and Solidification of Hazardous Wastes; VanNostrand Reinhold, Inc.: New York, 1989.

(2) Stabilization and Solidification of Hazardous, Radioactive and Mixed Wastes, 2nd Vol., ASTM STP 1123, Gilliam, T. M.; Wiles, C. C., eds., ASTM, Philadelphia, PA, 1992.

(3) Stabilization and Solidification of Hazardous, Radioactive and Mixed Wastes, 3rd Vol., ASTM STP 1240, Gilliam, T. M.; Wiles, C. C., eds., ASTM, Philadelphia, PA, 1996.

(4) Mattus, C. H.; Mattus, A. J. in Stabilization and Solidification of Hazardous, Radioactive, and Mixed Wastes, ASTM STP 1240 Gilliam, T. M. and Wiles, C. C., Ed.; American Society for Testing and Materials, 1996; Vol. 3.

(5) Owens, J. W.; Stewart, S. Magazine of Concrete Research 1996, 48, 37-44.

(6) Hills, C. D.; Pollard, S. J. T. J. Hazard. Mater. 1997, 52, 171-91.

(7) Taylor, H. F. W. Cement Chemistry; 2nd ed.; Thomas Telford Publishing: London, 1997.

(8) Glasser, F. P. J. Hazard. Mater. 1997, 52, 151-70.

(9) Lear, P. R.; Conner, J. R. Hydrocarbon Contam. Soils 1992, 2, 459-85.

(10) Spence, R. D.; Gilliam, T. M.; Morgan, I. L.; Osborne, S. C. "Stabilization/solidification of wastes containing volatile organic compounds in commercial cementitious waste forms" in "Stabilization and Solidification of Hazardous, Radioactive and Mixed Waste, 2nd Volume", STP 1123, M. Gilliam and C.Wiles, (eds.), ASTM, Philadelphia, 1992, pp. 61-72.

(11) Conner, J. R.; Lear, P. R. "Immobilization of low-level organic compounds in hazardous waste".: Proc., Annu. Meet.., Air Waste Manage, Assoc., 1991, 84th (vol.11), Paper 91/22.9, 18pgs.

(12) Sell, N. J.; Revall, M. A.; Bentley, W.; McIntosh, T. H. "Solidification and 
stabilization of phenol and chlorinated phenol contaminated soils":

"Stabilization and Solidification of Hazardous, Radioactive and Mixed Waste", 2nd Volume, STP 1123, M. Gilliam and C.Wiles, (eds.), ASTM, Philadelphia, 1992, pp. 73-85.

(13) Conner, J. R.; Cotton, S.; Lear, P. R. "Chemical stabilization of contaminated soils and sludges using cement and cement byproducts": Cement Industry Solutions To Waste Management, Proc. 1st Intl. Symp., Calgary, Oct. 1992, Canadian Portland Cement Assoc., Toronto, 1992, pp. 73-97.

(14) Adaska, W. S.; Ten Bruin, W.; Day, S. R. "Remediation of oil refinery sludge basin": Cement Industry Solutions To Waste Management, Proc. 1st Intl. Symp., Calgary, Oct. 1992, Canadian Portland Cement Assoc., Toronto, 1992, pp. 119-134.

(15) Barth, E. F.; de Percin, P.; Arozarena, M. M.; Zieleniewski, J. L.; Dosani, M.; Maxey, H. R.; Hokanson, S. A.; Pryately, C. A.; Whipple, T.; Kravitz, R.; Cullinane, M. J.; Jones, L. W.; Malone, P. G. Stabilization and Solidification of Hazardous Wastes, Noyes Data Corp., Park Ridge, NJ, 1990, pp. 14-17.

(16) Brown, R. E.; Jindal, B. S.; Bulzan, J. D. "A critical review of the effectiveness of stabilization and solidification of hazardous organic wastes": "Stabilization and Solidification of Hazardous, Radioactive and Mixed Waste", 2nd Volume, STP 1123, M. Gilliam and C.Wiles, (eds.), ASTM, Philadelphia, 1992, pp. 43-60.

(17) Sutton, C. C., J. A. J. Chem. Eng. Data 1975, 20, 320-322.

(18) Herman, G. T. Image Reconstruction From Projections: The Fundamentals of Computerized Tomography; Academic Press: New York, 1980.

(19) R. B. Marr, "Fast Filtered Back-Transform Reconstruction Algorithm for Generalized Fourier Data", Soc. Of Magnetic Resonance in Med., 6th Annual Meeting (August 17-21, 1987).

(20) Dowd, B. A.; Andrews, A. B.; Marr, R. B.; Siddons, D. P.; Jones, K. W.; Peskin, A. M. "Advances in X-Ray Computed Microtomography at the NSLS", invited paper, presented at the 47th Annual Denver X-Ray Conference, Colorado Springs, CO, August 3-7, 1998, to be published in Adzances in X-ray Analysis, Vol. 42, May, 1999.

(21) Lippmaa, E.; Mägi, M.; Samoson, A.; Engelhardt, G.; Grimmer, A.-R. J. Am. Chem. Soc. 1980, 102, 4889-3.

(22) Engelhardt, G.; Koller, H. NMR Basic Principles and Progress 1994, 31, 1-29. 
(23) Janusa, M. A.; Wu, X.; Cartledge, F. K.; Butler, L. G. Environ. Sci. Technol. 1993, 27, 1426-33.

(24) Schmidt-Rohr, K.; Spiess, H. W. Multidimensional Solid-State NMR and Polymers; Academic Press: New York, 1994.

(25) Russ, J. C. The Image Processing Handbook; 2nd ed.; CRC Press: Boca Raton, 1994.

(26) Lohmann, G. Volumetric Image Analysis; Wiley-Teubner: New York, 1998.

(27) Fanning, D. W. IDL Programming Techniques; Fanning Software Consulting: Fort Collins, CO, 1997.

(28) Adamson, A. W. Physical Chemistry of Surfaces; 4th ed.; John Wiley: New York, 1982.

(29) Billingham, J.; Coveney, P. V. J. Chem. Soc., Faraday Trans. 1993, 89, 3021-8.

(30) Wattis, J. A. D.; Coveney, P. V. J. Chem. Phys. 1997, 106, 9122-40.

(31) Cong, X.; Kirkpatrick, R. J. Cement and Concrete Research 1993, 23, 1065-77.

(32) Brough, A. R.; Dobson, C. M.; Richardson, I. G.; Groves, G. W. J. Am. Ceram. Soc. 1994, 77, 593-96.

(33) Ref. 7, Table 1.2.

(34) Ref. 7, p. 126. 


\section{List of Figures}

1. Microtomography images of (a) 1.24 and (b) $2.49 \mathrm{wt} \%$ toluene/cement rendered to show vesicles in cement. The image dimensions are $0.972 \mathrm{~mm} \times 0.972 \mathrm{~mm} \times 0.583$ $\mathrm{mm}(150 \times 150 \times 70$ voxel data sets), corresponding to a $1 \mathrm{mg}$ sample mass and a 15 Mbyte data set.

2. Isosurfaces of (a) 1.24 and (b) $2.49 \mathrm{wt} \%$ toluene/cement drawn to show the vesicle structure. The isosurfaces enclose volumes with an $X$-ray absorptivity of $3.3 \times 10^{-4}$ O.D./voxel or less.

3. The microtomography results show only a small fraction of initial toluene is encapsulated in vesicles. For $0-2.5 \mathrm{wt} \%$ toluene/cement, the $\mathrm{wt} \%$ toluene in vesicles is modeled (solid line) with a threshold for vesicle formation of $0.7 \mathrm{wt} \%$ toluene/cement, followed by a linear function. For $>3 \mathrm{wt} \%$ toluene/cement, toluene pools atop the cement during sample preparation, and a near constant $\mathrm{wt} \%$ toluene in vesicles is then expected (dashed line). The dotted line represents the limiting behavior if all toluene is encapsulated in vesicles. The difference between the dotted and solid lines is the toluene dispersed in cement, as shown in the insert.

4. Backscatter electron image of (a) $0 \mathrm{wt} \%$ and (b) $3.58 \mathrm{wt} \%$ toluene/cement samples. Magnification is approximately $1000 \mathrm{x}$, and a bar scale representing $10 \mu \mathrm{m}$ is included. This pair of images was taken in a search for possible $1-20 \mu \mathrm{m}$ vesicles in the $3.58 \mathrm{wt} \%$ sample, not present in the $0 \mathrm{wt} \%$ sample. Since a large number of such vesicles is not found, the conclusion is made that the large fraction of toluene not contained in the $20-250 \mu \mathrm{m}$ vesicles must be intimately dispersed in the cement matrix. Numbers represent analytical points found in Figure 5. High greyscale contrast points such as 10,11,3, and 4, apparently represent grains of unreacted tricalcium silicate, whereas the intermediate greyscale points such as 12 , $13,5-8$, apparently represent a range of complex hydration products. 
5. EPMA elemental analysis of $0 \mathrm{wt} \%$ and $3.58 \mathrm{wt} \%$ toluene/cement samples. Unreacted tricalcium silicate grains have typical compositions. 33 Reaction products are likely mixtures of hydrous calcium silicate, calcium hydroxide, and other materials, and again have compositions, including total levels of hydration, about $25 \mathrm{wt} \%$, typical of reacted cements. 34 The minor differences in the reaction zone chemistry between the two samples does not provide proof that toluene is well dispersed in the cement matrix.

6. ${ }^{29} \mathrm{Si}$ MAS NMR spectra of toluene/cement samples. The Q0 resonance at -70 ppm is largely due to unreacted orthosilicate. As the toluene content increases, there is a reduction in the amplitude of the $\mathrm{Q}_{2}$ resonance at $-84 \mathrm{ppm}$, indicating a reduced chain silicate formation, and thus, intimate mixing of toluene with the cement paste. Spinning sidebands are labeled $(*)$. Legend for sample numbers in (). 
(a) $1.24 \mathrm{wt} \%$ toluene/cement

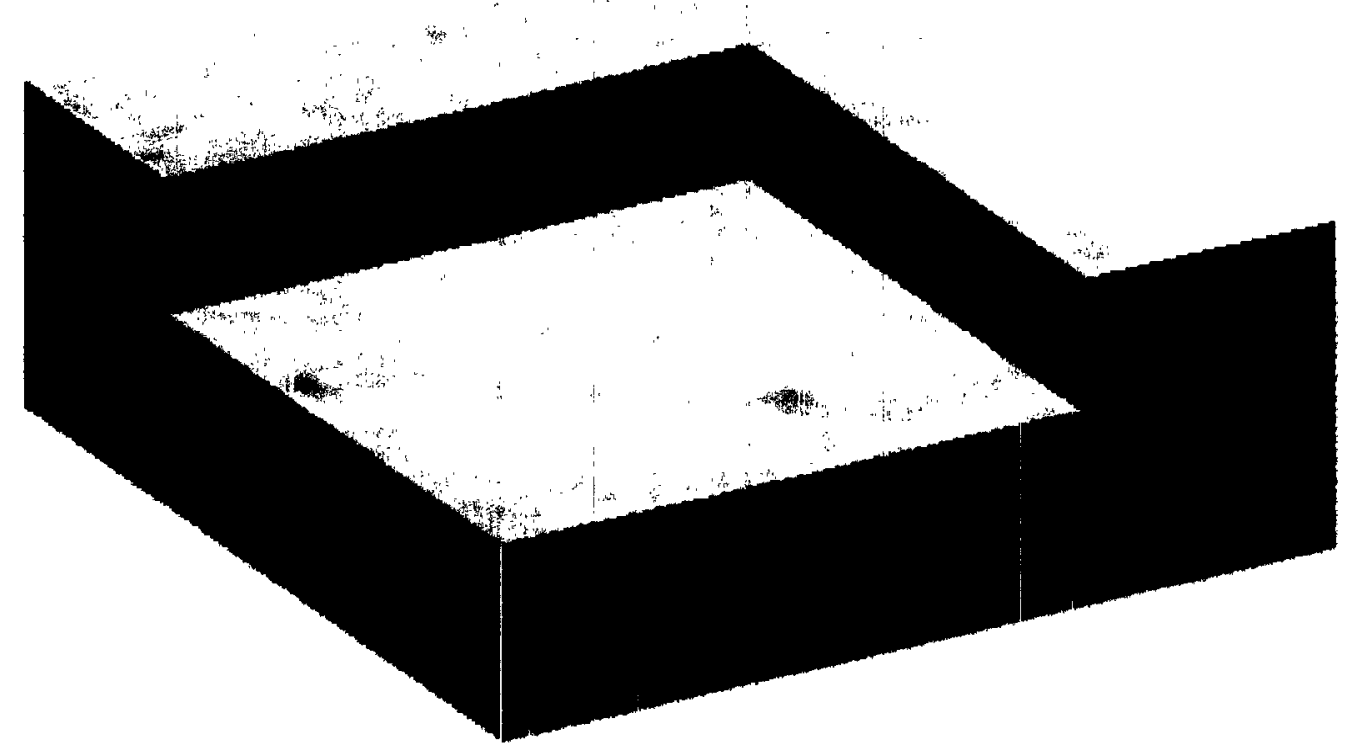

(b) $2.49 \mathrm{wt} \%$ toluene/cement

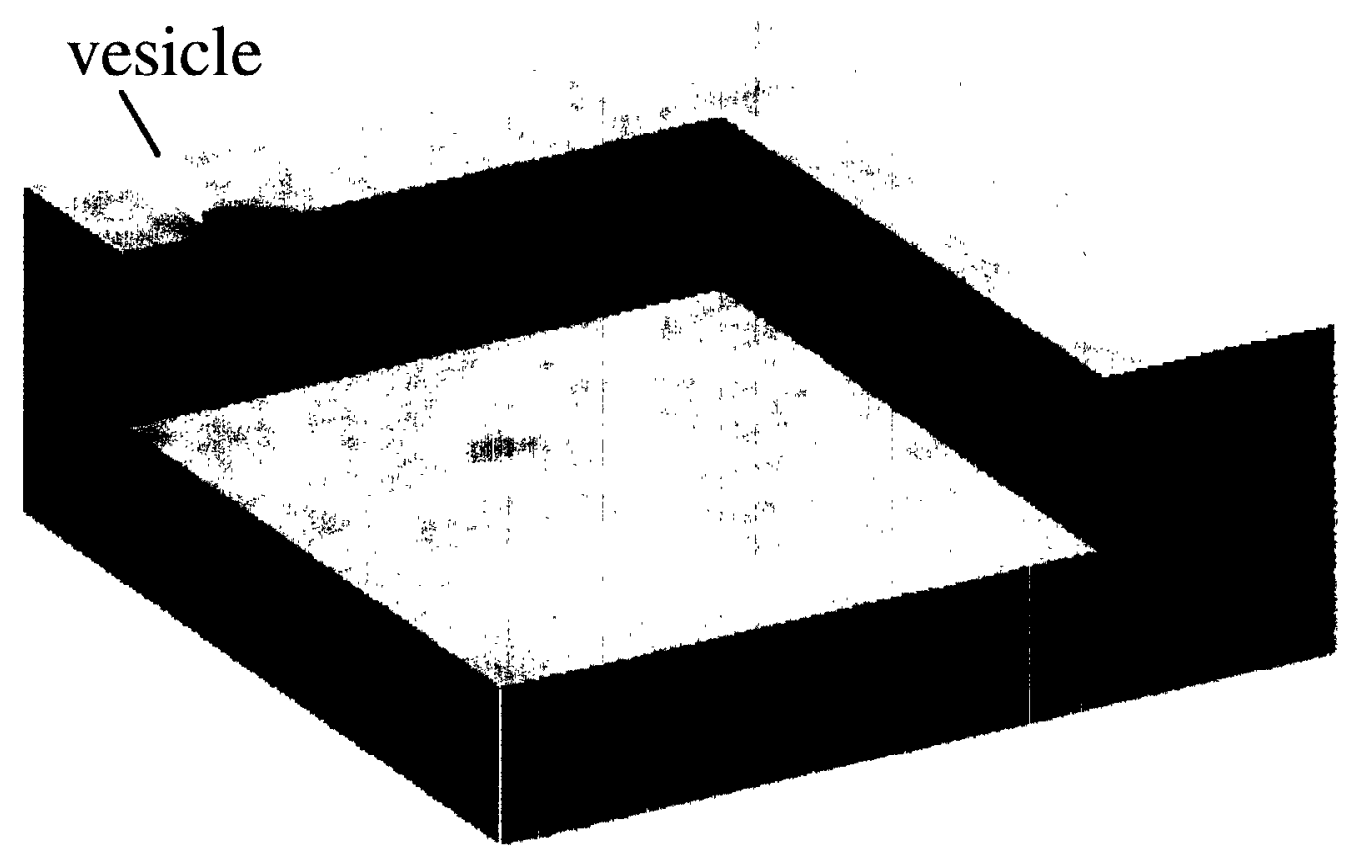

Fig 1. 
(a) $1.24 \mathrm{wt} \%$ toluene/cement

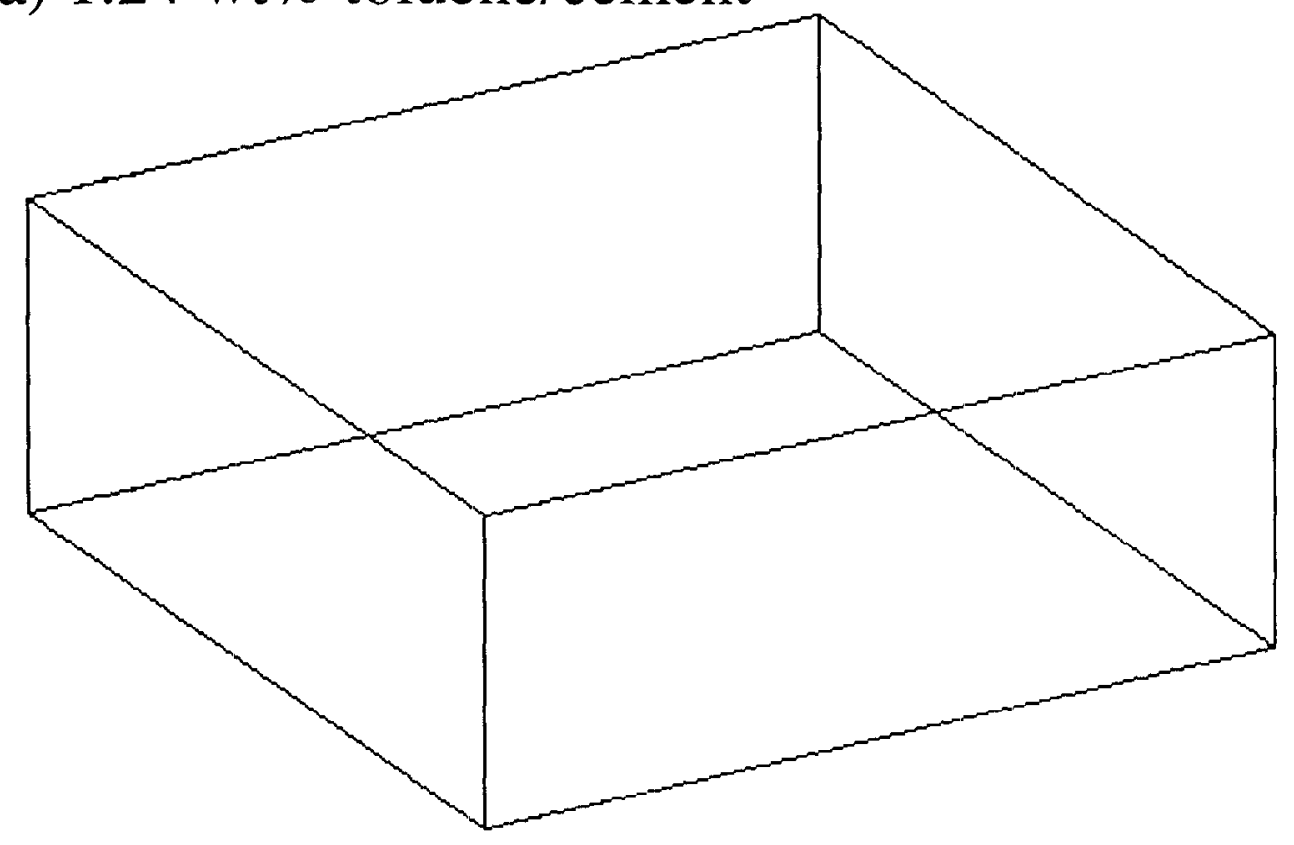

(b) $2.49 \mathrm{wt} \%$ toluene/cement

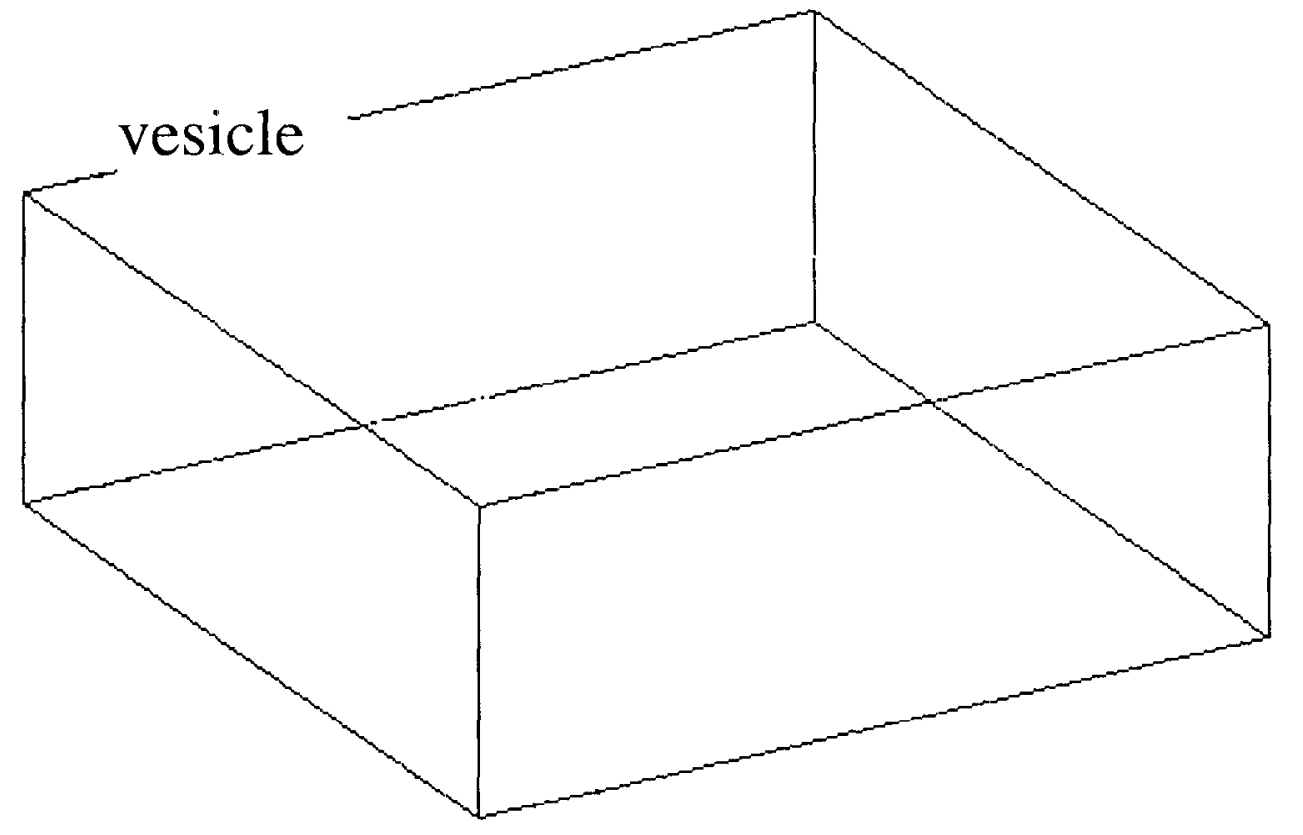

Fig 2 


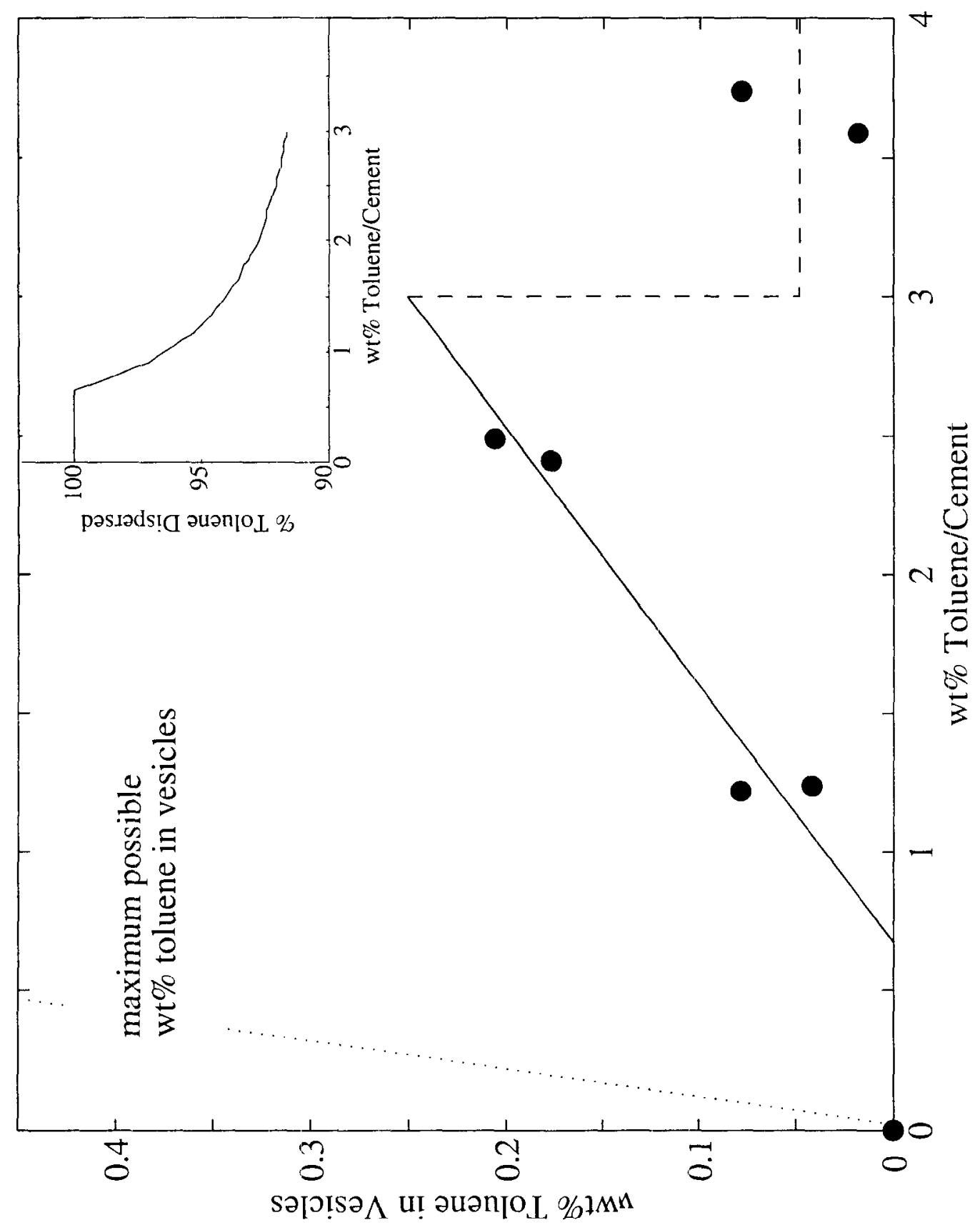




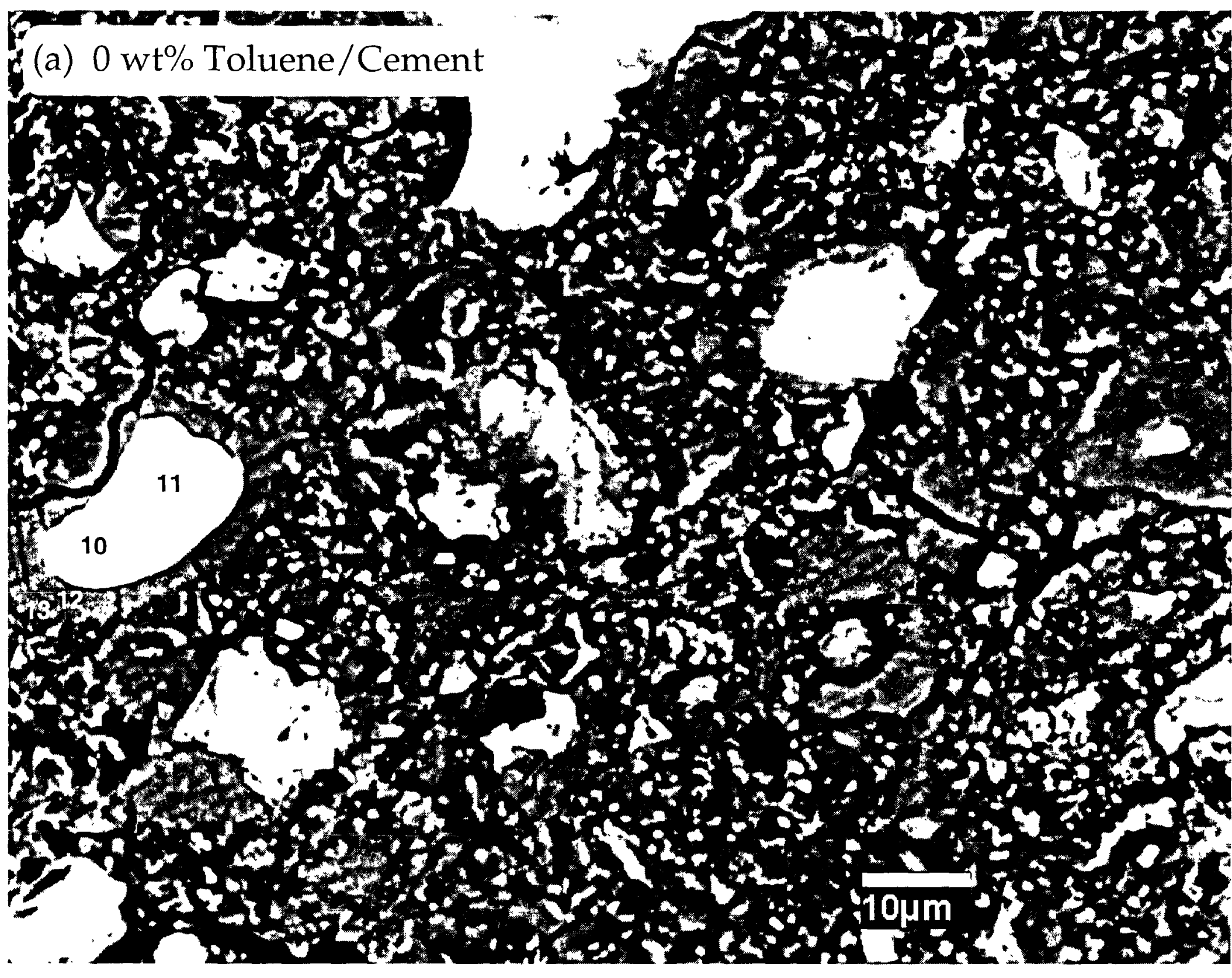

S4b1000MPS black-white ct

Fig $4 \mathrm{a}$ 


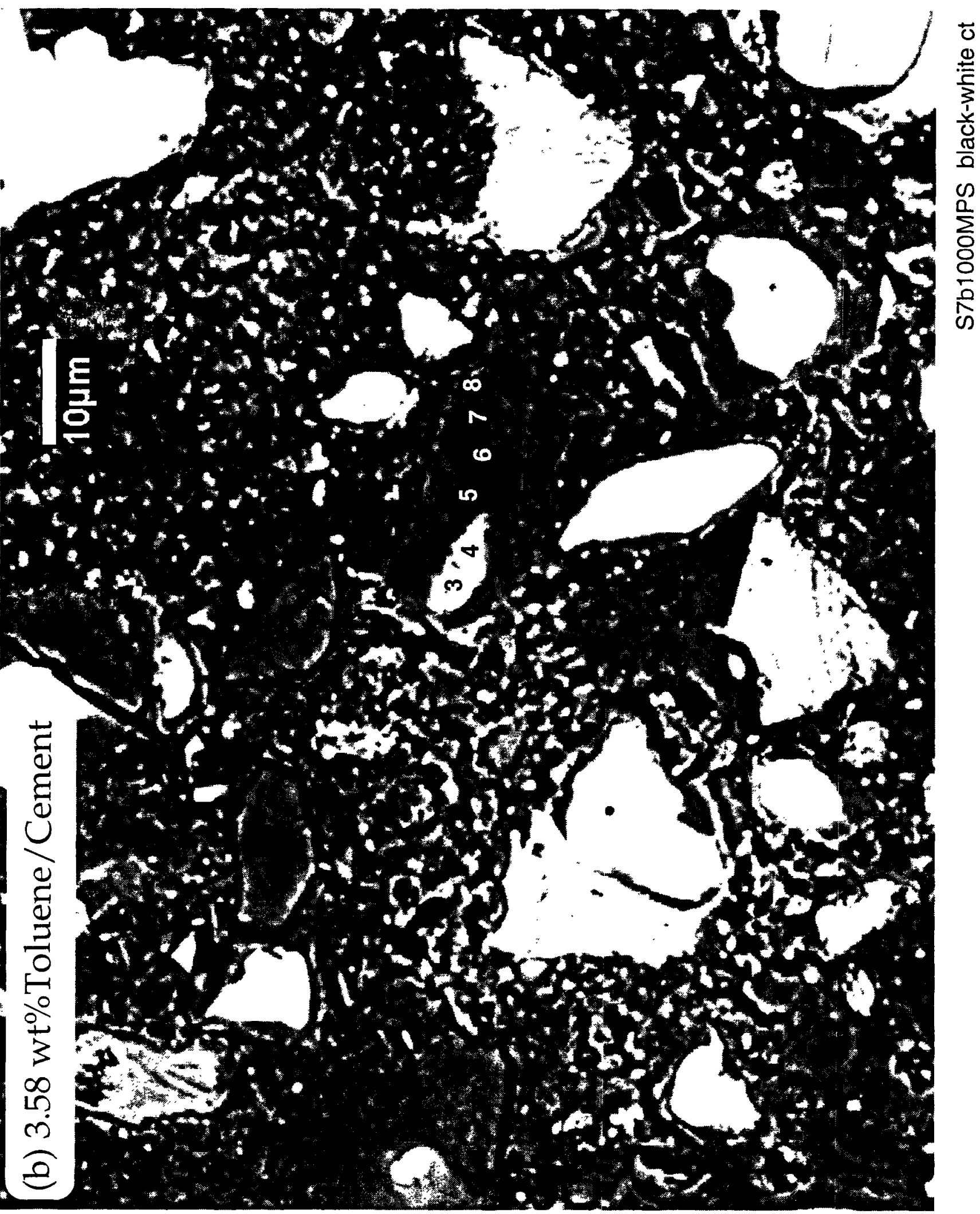




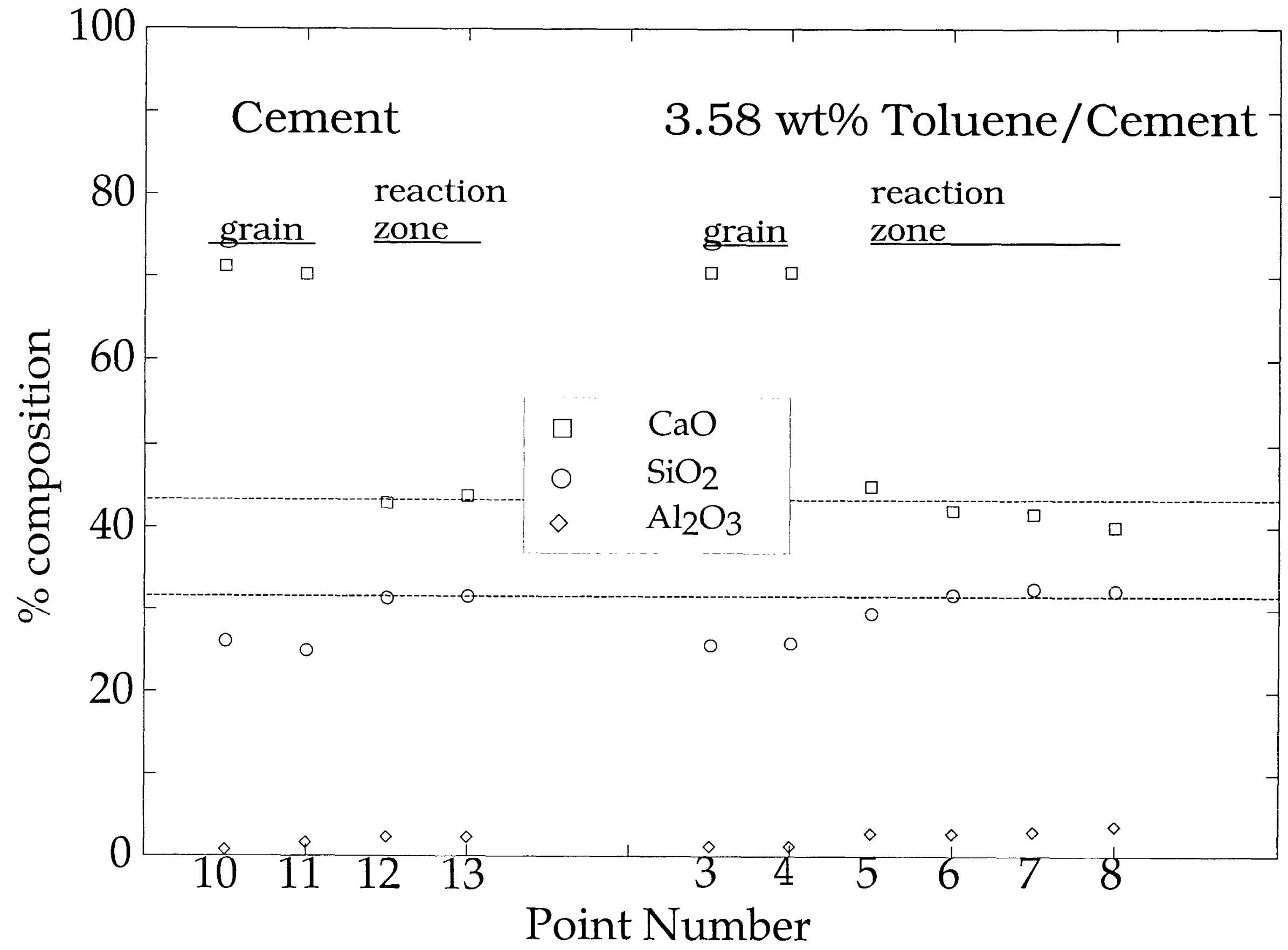

Fig. 5 


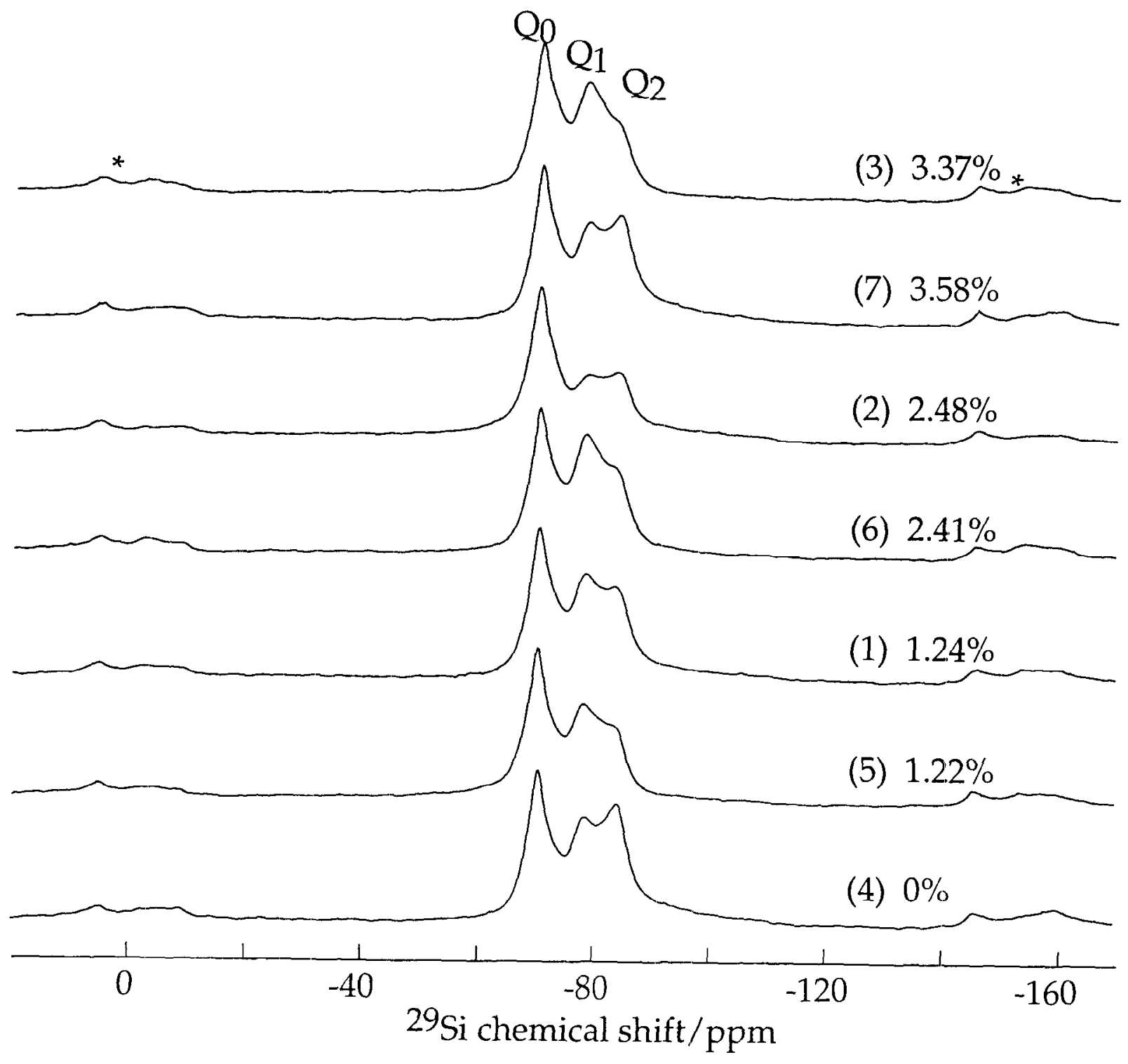

Fig. 6 


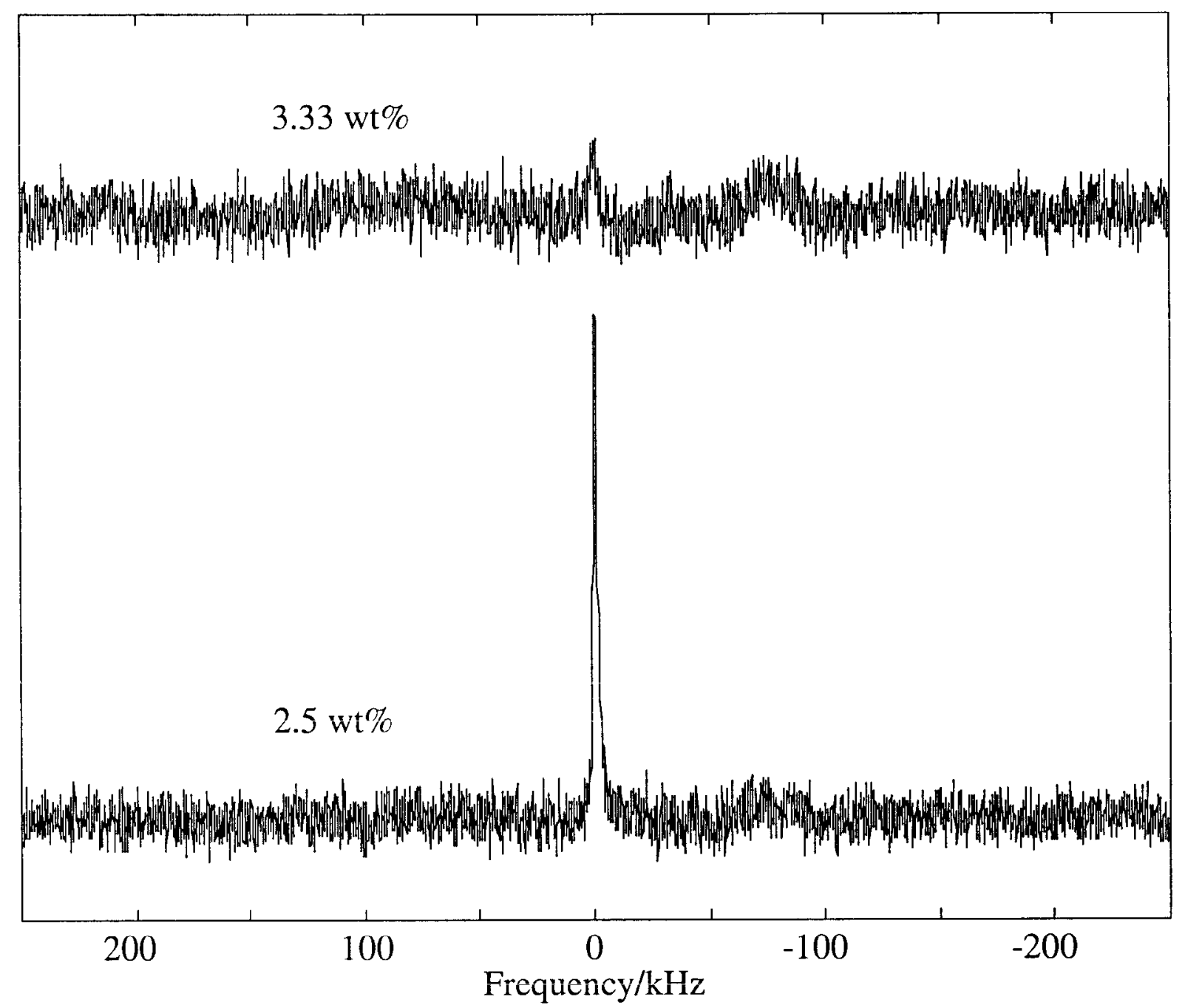

Fig 7 